\title{
Research on Evolutionary Game of Engineering Community Members from the Perspective of Engineering Ethics
}

\author{
Ziming Zhu ${ }^{1, *}$, Yuanzhen Song ${ }^{1}$, Menglin Qin ${ }^{1}$ \\ ${ }^{1}$ College of Civil and Architecture Engineering, Guangxi University, 530004, China
}

\begin{abstract}
Engineering ethics is a system of ethical principles applied to engineering, which plays the role of value guidance and criterion evaluation in engineering construction activities. Based on engineering ethics, writers review the Sanmenxia Reservoir Project, and use system dynamics to systematically study the evolutionary game of engineering community members, including government, enterprise, and people, involved in the engineering activities. The results show that the engineering community is a heterogeneous community with complex game behaviors, and the correct ethical choice is the key factor that promotes the evolution of the community members to cooperative dynamic equilibrium. Good management of ethical commitment, emphasis on professionalism and public services, strengthening risk alert and avoidance are effective ways for members of the engineering community to form a cooperative game, avoid tragedy of public resources, and ultimately ensure the orderly development of projects.
\end{abstract}

\section{Introduction}

Since 1949, in order to pursue the rapid development of economy and society, China has carried out many largescale engineering constructions, which brought great improvements to the urbanization process and people's living standards and had many negative impacts on resources, the environment and social groups. The engineering community is the leader of engineering construction, and its values and purposes exist as the preexisting logic of engineering construction [1]. Adversarial games among each other are the main factors that result in improper ethical behaviors and "problem engineering". Nowadays, with the stricter control of engineering construction, it is urgent to study the interactive game behaviors of community members from the perspective and method of engineering ethics, and correct the ethical logic between game subjects in order to effectively restrict and supervise engineering activities and engineering activities and give participating subjects correct education on ethics.

In the $1980 \mathrm{~s}$, a number of modern engineering appeared, and the concept of "big project" was first proposed abroad [2]. Since then, most of the engineering construction has been considered as a social, integrated, and holistic ethical production activity. Traditionally, the subject of the project has been considered to be single engineers. However, it has gradually changed to be "Engineering Community" compositing of complex heterogeneous members. Later, G.F.C.Rogers et al. [3] began to explore the nature of engineering, arguing that engineering is a technological philosophy, and they carried out related researches on the philosophy of the engineering community; Walter G. Vincenti et al. [4] published Knowledge of Engineers, considering the key points of the cooperation of the engineering community is the engineer and focusing on the status of the engineer; In Design Engineer and Engineering Philosophy, Louis L. Bucciarelli et al. [5, 6] focused on the analysis of engineering design procedures and methods, and analyzed the related responsibilities of engineers and other community members in engineering activities.

Foreign academic circles have conducted a comprehensive discussion on engineering ethics and the engineering behaviors of engineers, but the related researches on members of the engineering community are not thorough and few of them analyzed the complex social composition and feedback mechanism between members in engineering activities. Li Bocong, the pioneer of the study of engineering philosophy in China, has carried out related researches on the ethical responsibility of the engineering community. In Engineering Innovation and Engineering Talents, Several Questions about Engineers, Research on Engineering Community and Pioneering of Engineering Sociology and other works and literature, he specifically elaborated the scope of the engineering community and the ethical responsibility; Zhang Zhiyun et al. focused on the composition and characteristics of the engineering community; Li Sanhu analyzed the division of labor and cooperation among members of the engineering community in engineering activities; Zhang Hengli, Hu Xinhe et al. discussed engineering ethics and its influence on the behaviors of community members. Looking back on domestic researches, the ethics and responsibilities of the engineering community have been extensively discussed [7, 8, 9]. However, they are confined to the analysis of the external ethical 
responsibilities of the engineering community, but have fewer discussions on internal ethics and interactive game. Therefore, based on engineering ethics, this article takes the Sanmenxia Water Control Project for example. It is planned to use the vensim platform to simulate the internal evolutionary game behavior of tripartite members of engineering community (government, enterprise, and people) during the development of the project, analyze the evolutionary and stable trend of the stakeholder under different returns, find out the key ethical factors affecting the equilibrium state of the game and propose game strategies catering to conspiracy behavior of members of engineering community.

\section{Definition of related concepts}

\subsection{Engineering Ethics}

Engineering ethics is a system of ethical principles that originated in ethics and applied to engineering [10]. Engineering ethics plays a role in engineering construction and technology development. It belongs to applied ethics and is a code of conduct for people in engineering activities, including codes of conduct and ethical standards formulated by engineering organizations and related associations. The core is ethical responsibilities of engineering subjects such as governments, developers, engineers, etc. Engineering ethics, as a standard and educational goal, is conducive to improving the ethical quality of engineers, strengthening the social responsibilities of engineering practitioners, coordinating the interest relationships between social groups, and ultimately promoting the harmonious development of engineering and social economy.

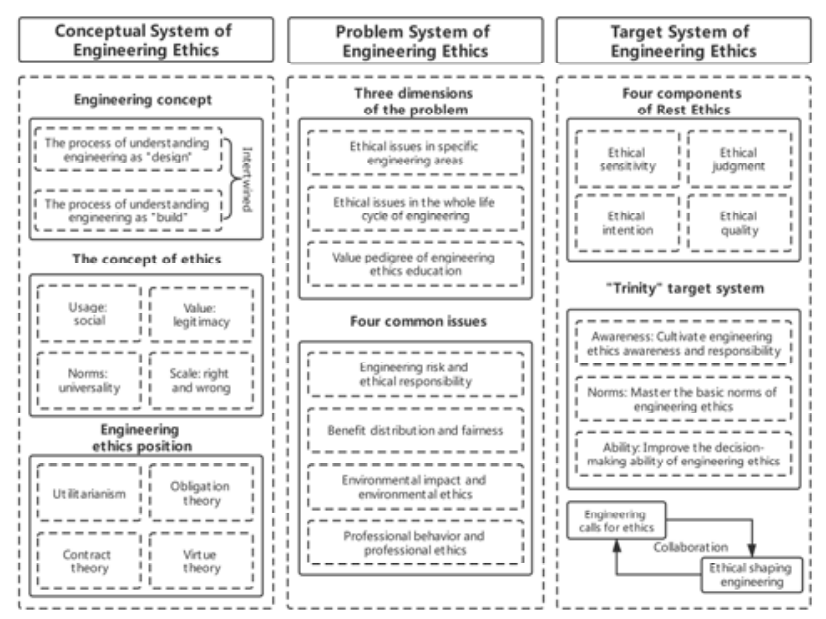

Fig. 1. Theoretical system of Engineering Ethics.

\subsection{Engineering Community}

Community is a group or an organization that connects all kinds of people into a whole of action by an internal factor, thereby providing a comprehensive and scientific vision for a certain human behavior. Engineering activities are large-scale technical and economic activities in human society and have specific value target guidelines. Therefore, the engineering community is inherently a community of interests and a participating group throughout the entire life cycle of engineering activities [11]. It is based on the engineering paradigm, with the goal of engineering design, construction and management. It includes multiple types of members: investors, entrepreneurs, managers, engineers, workers, influential people, etc. It is a "heterogeneous member community" composed of various stakeholders.

\subsection{Evolutionary Games}

Evolutionary games belong to the category of game theory, which mainly studies the evolutionary interaction between incentive structures. They mainly studied the evolutionary interaction between the incentive structures and became dynamic and competitive mathematical theories and methods [12]. Evolutionary games combine game equilibrium and dynamic selection mechanisms to simulate the dynamic game process of multiple game players. The specific work of it is to use mathematical models and systems science to analyze the process and reasons for game players to reach an evolutionary equilibrium state. The evolutionary game considers the predictive simulation behaviors and actual development behaviors of game players among the systems, and finally formulates optimal strategies of the system, which includes four steps (information, strategy, income, equilibrium) and three game rules(man, action, and result).

\section{Background and model building}

\subsection{Overview of the research area}

Sanmenxia Reservoir is the first comprehensive water conservancy project built in New China that has multiple functions such as flood control, flood control, power generation, irrigation, and water supply [13], located at the junction of Sanmenxia in Henan Province and Pinglu in Shanxi Province. The construction began at 1957 and was completed and put into operation in 1960. Due to the lack of great planning, design and social collaboration, problems such as silt deposition occurred in the Sanmenxia Dam, which had a negative impact on the ecology of the upper reaches of the dam, resulting in salinity and swamps in the fields. At the same time, there are fewer social forces involved in the construction process, capital withdrawal and financing difficulties, and subsequent project guarantees are very insufficient. In addition, improper development has resulted in many social and environmental problems, such as fugitive resettlements, the occupation of large quantities of cultivated land, destructions of historic sites, and damages in the aspect of social and ecological balance in the reservoir area.

After the emergence of many problems in the Sanmenxia Reservoir, the government and social groups began to realize that the construction of the project is not only rely on the government or a simple application of 
technology. The fundamental attribute of the project is sociality, which determines that social factors are not optional externalities but endogenous variables of the project. The failure of the first construction of the Sanmenxia Reservoir Project is not only due to insufficient technology, but also due to the government's inadequate communications with social groups, lack of struggles in resettlement affecting the public and bad cooperative relationship with enterprises. In order to make up for the situation, the government and social groups began to seek improvements in the Sanmenxia Reservoir. After two reconstructions, this project was temporarily saved in the 1960s,

\subsection{Technical route}

On the basis of identifying the concepts of "engineering ethics", "engineering community" and "evolutionary game", and using engineering ethics as the theoretical basis, an evolutionary game will be initiated on the three members of the community members "government, enterprise, and people" involved in the development of the Sanmenxia Reservoir. We will use system dynamics to simulate the three-party game relationship by inputting a series of data on the vensim platform to construct the "evolutionary game system flow model of members of the engineering community" affected by the sanmenxia reservoir project activities, so as to deduce the evolutionary game equilibrium and sensitivity among members. Finally, we will be able to analyze the expected game emphases and countermeasures of three kinds of games guided by engineering ethics.

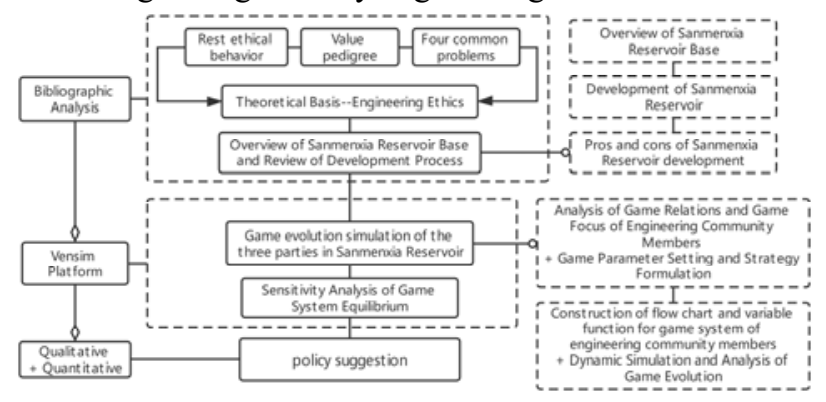

Fig. 2. Technical route of research.

\subsection{Model construction}

This model takes "government, enterprise, and people" as members of the engineering community in the construction of the Sanmenxia Reservoir, combines the causality and feedback control of the game among the three subjects in project development, constructs a revenue function and establishes the equation of the evolutionary game for members of the engineering community. By changing the internal structure and external parameters of the model, the game sensitivity of the three parties in different development scenarios can be explored. Writers sort out the feedback relationship between system elements, arrange the input and output order of material flow and information flow, and then draw a system flow model of the evolutionary game of the members of the engineering community in this paper, which intuitively reflects the mutual feedback structure in the game among "government, enterprise, and people", as shown in the Figure 3.

The data amount of system elements is input into vensim platform, which is represented by state variables, rate variables, auxiliary variables, and exogenous variables. Among them, Stock is stock function, which represents the cumulative income of the game subject; Inflow is inflow function, which represents the external income inflow value of the game subject; Outflow is outflow function, which represents the internal negative loss output value of the game subject.

In this model, the state variables are the cumulative quantities, which represent the cumulative stocks of three parties. whose mathematical meaning is integral:

$\operatorname{Stock}(t)=\int_{t_{0}}^{t}[\operatorname{Inflow}(s)-$ Outflow $(s)] d s+\operatorname{Stock}\left(t_{0}\right)$

The rate variable is the flow rate, which is the net rate of change of the state variable. The mathematical meaning is differential:

$$
d(\text { Stock }) / d t=\operatorname{Inflow}(t)-\text { Outflow }(t)
$$

Simulation of system dynamics is relied on vensim platform. The initial values of the model variables are set to: INITIAL TIME=0, FINAL TIME=20, TIME STEP $=1$, UNITS FOR TIME: YEAR. Model parameters are mainly applied to describe and form functions and empirical equations that constitute system variables: use the "Lookup" function to calculate variables with relatively complete data to describe the discretized nonsmooth curves of complex nonlinear relationships; use multiple regression The statistical analysis calculates the variables with relatively incomplete data. In the SPSS derivation, if the correlation coefficient is $>0.6$ and the significance coefficients are $<0.05$, the function formula with a good fitting result is output. The formulas of parameters and variables in the flow diagram of the game system are shown in Table 1.

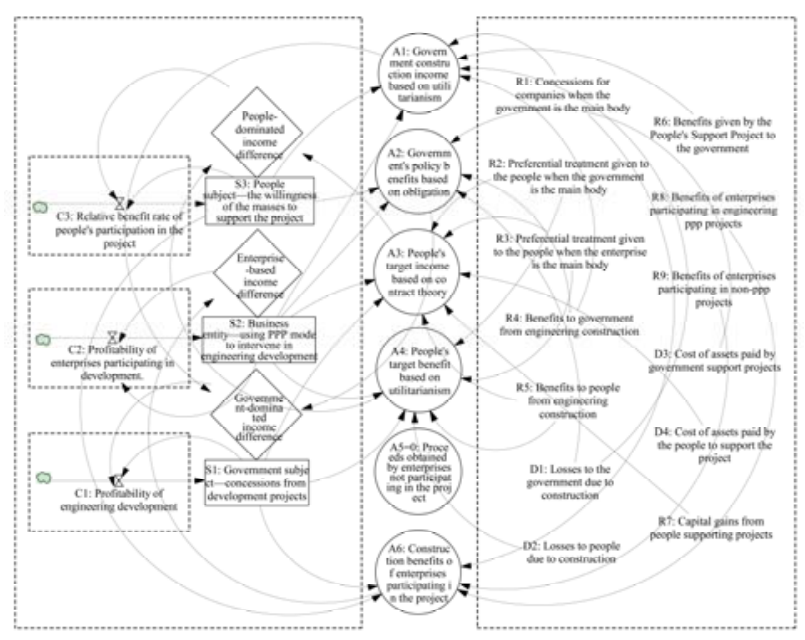

Fig. 3. Evolution game system flow diagram of engineering community members. 
Table 1. Description of model parameters.

\begin{tabular}{|c|c|c|c|c|}
\hline Variable & Symbol & System indicators & System equations and constants & Unit \\
\hline \multirow{3}{*}{$\begin{array}{c}\text { State } \\
\text { variables }\end{array}$} & S1 & $\begin{array}{l}\text { Government subject_concessions } \\
\text { from development projects }\end{array}$ & $=$ INTEG[EXP(S1, C1 $), 0]$ & DMNL \\
\hline & $\mathrm{S} 2$ & $\begin{array}{l}\text { Business entity_using PPP mode to } \\
\text { intervene in engineering }\end{array}$ & $=\mathrm{INTEG}[\mathrm{EXP}(\mathrm{S} 2, \mathrm{C} 2), 0]$ & DMNL \\
\hline & $\mathrm{S} 3$ & $\begin{array}{l}\text { People subject the willingness of } \\
\text { the masses to support the project }\end{array}$ & $=\mathrm{INTEG}[\mathrm{EXP}(\mathrm{S} 3, \mathrm{C} 3), 0]$ & DMNL \\
\hline \multirow{3}{*}{$\begin{array}{c}\text { Rate } \\
\text { variable }\end{array}$} & $\mathrm{C} 1$ & $\begin{array}{c}\text { Profitability of engineering } \\
\text { development }\end{array}$ & $=\{\mathrm{S} 1 * \ln [(\mathrm{A} 1-\mathrm{A} 2) /(\mathrm{A} 1+\mathrm{A} 2)]\}$ & DMNL \\
\hline & $\mathrm{C} 2$ & $\begin{array}{l}\text { Profitability of enterprises } \\
\text { participating in development. }\end{array}$ & $=\{\mathrm{S} 1 * \ln [\mathrm{A} 6 /(\mathrm{A} 6+\mathrm{R} 8+\mathrm{R} 9)\}$ & DMNL \\
\hline & $\mathrm{C} 3$ & $\begin{array}{l}\text { Relative benefit rate of people's } \\
\text { participation in the project }\end{array}$ & $=\{\mathrm{S} 1 * \ln [(\mathrm{A} 3-\mathrm{A} 4) /(\mathrm{A} 3+\mathrm{A} 4)\}$ & DMNL \\
\hline \multirow{6}{*}{$\begin{array}{l}\text { Auxiliary } \\
\text { variable }\end{array}$} & A1 & $\begin{array}{l}\text { Government construction income } \\
\text { based on utilitarianism }\end{array}$ & $\begin{aligned}= & \{\mathrm{S} 3 *[\mathrm{~S} 2 *(\mathrm{R} 4-\mathrm{R} 1)+\mathrm{R} 6 *(1-\mathrm{S} 2)] \\
& +\mathrm{S} 2 *(1-\mathrm{S} 3) *(\mathrm{R} 4-\mathrm{R} 1-\mathrm{D} 1)\}\end{aligned}$ & DMNL \\
\hline & A2 & $\begin{array}{l}\text { Government's policy benefits based } \\
\text { on obligation }\end{array}$ & $\begin{aligned}= & \{\mathrm{S} 3 *[\mathrm{~S} 2 *(\mathrm{R} 4-\mathrm{D} 3)+(1-\mathrm{S} 2) *(\mathrm{R} 4-\mathrm{D} 3)]+\mathrm{S} 2 *(1- \\
\mathrm{S} 3) & \\
& *(\mathrm{R} 4-\mathrm{D} 3-\mathrm{D} 1)+(1-\mathrm{S} 3) *(1-\mathrm{S} 2) *(\mathrm{R} 4-\mathrm{D} 3-\mathrm{D} 1)\}\end{aligned}$ & DMNL \\
\hline & $\mathrm{A} 3$ & $\begin{array}{l}\text { People's target income based on } \\
\text { contract theory }\end{array}$ & $\begin{aligned}= & \{\mathrm{S} 1 * \mathrm{~S} 2 *(\mathrm{R} 3+\mathrm{R} 5)+\mathrm{S} 1 *(1-\mathrm{S} 2) *(\mathrm{R} 7+\mathrm{R} 5-\mathrm{D} 4) \\
& +(1-\mathrm{S} 1) *[\mathrm{~S} 2 *(\mathrm{R} 2+\mathrm{R} 5)+(1-\mathrm{S} 2) *(\mathrm{R} 2+\mathrm{R} 5)]\}\end{aligned}$ & DMNL \\
\hline & A4 & $\begin{array}{l}\text { People's target benefit based on } \\
\text { utilitarianism }\end{array}$ & $\begin{array}{c}=\{\mathrm{S} 1 * \mathrm{~S} 2 *(\mathrm{R} 3+\mathrm{R} 5-\mathrm{D} 2)+(1-\mathrm{S} 1) * \mathrm{~S} 2 *(\mathrm{R} 2+\mathrm{R} 5-\mathrm{D} 2) \\
+(1-\mathrm{S} 1) *(1-\mathrm{S} 2) *(\mathrm{R} 2+\mathrm{R} 5-\mathrm{D} 2)\}\end{array}$ & DMNL \\
\hline & A5 & $\begin{array}{l}\text { Proceeds obtained by enterprises not } \\
\text { participating in the project }\end{array}$ & $=0$ & DMNL \\
\hline & A6 & $\begin{array}{l}\text { Construction benefits of enterprises } \\
\text { participating in the project }\end{array}$ & $\begin{array}{c}=\{\mathrm{S} 1 * \mathrm{~S} 3 *(\mathrm{R} 1+\mathrm{R} 8)+\mathrm{S} 1 *(1-\mathrm{S} 3) *(\mathrm{R} 1+\mathrm{R} 8)+(1-\mathrm{S} 1) \\
* \mathrm{~S} 3 * \mathrm{R} 9+(1-\mathrm{S} 1) *(1-\mathrm{S} 3) * \mathrm{R} 9\}\end{array}$ & DMNL \\
\hline \multirow{13}{*}{$\begin{array}{l}\text { Exogenous } \\
\text { variable }\end{array}$} & $\mathrm{R} 1$ & $\begin{array}{l}\text { Concessions for companies when } \\
\text { the government is the main body }\end{array}$ & $=\operatorname{Lookup}\{[(0,20)-(10,80)]\}$ & DMNL \\
\hline & $\mathrm{R} 2$ & $\begin{array}{l}\text { Preferential treatment given to the } \\
\text { people when the government is the } \\
\text { main body }\end{array}$ & $=\operatorname{Lookup}\{[(0,20)-(2,20)]\}$ & DMNL \\
\hline & $\mathrm{R} 3$ & $\begin{array}{l}\text { Preferential treatment given to the } \\
\text { people when the enterprise is the } \\
\text { main body }\end{array}$ & $=\operatorname{Lookup}\{[(0,20)-(1,5)]\}$ & DMNL \\
\hline & $\mathrm{R} 4$ & $\begin{array}{l}\text { Benefits to government from } \\
\text { engineering construction }\end{array}$ & $=\operatorname{Lookup}\{[(0,20)-(40,200)]\}$ & DMNL \\
\hline & R5 & $\begin{array}{l}\text { Benefits to people from engineering } \\
\text { construction }\end{array}$ & $=\operatorname{Lookup}\{[(0,20)-(0,15)]\}$ & DMNL \\
\hline & R6 & $\begin{array}{l}\text { Benefits given by the People's } \\
\text { Support Project to the government }\end{array}$ & $=\operatorname{Lookup}\{[(0,20)-(25,200)]\}$ & DMNL \\
\hline & R7 & $\begin{array}{l}\text { Capital gains from people } \\
\text { supporting projects }\end{array}$ & $=\operatorname{Lookup}\{[(0,20)-(0,12)]\}$ & DMNL \\
\hline & $\mathrm{R} 8$ & $\begin{array}{l}\text { Benefits of enterprises participating } \\
\text { in engineering ppp projects }\end{array}$ & $=20$ & DMNL \\
\hline & R9 & $\begin{array}{l}\text { Benefits of enterprises participating } \\
\text { in non-ppp projects }\end{array}$ & $=5$ & DMNL \\
\hline & D1 & $\begin{array}{l}\text { Losses to the government due to } \\
\text { construction }\end{array}$ & $=20$ & DMNL \\
\hline & D2 & Losses to people due to construction & $=5$ & DMNL \\
\hline & D3 & $\begin{array}{l}\text { Cost of assets paid by government } \\
\text { support projects }\end{array}$ & $=40$ & DMNL \\
\hline & D4 & $\begin{array}{l}\text { Cost of assets paid by the people to } \\
\text { support the project }\end{array}$ & $=5$ & DMNL \\
\hline
\end{tabular}




\section{Results and analysis}

The analysis and calculation of the parameters of the evolutionary game model shows that the evolutionary game of the members (government, enterprise, and people) in engineering community must be balanced (just the set of initial value). However, the simple parameter setting and system elements in series do not show the formation process and rate of change of such an equilibrium, which cannot fully explain the cause of such equilibrium. Thus, it is necessary to carry out parameter adjustment sensitivity analysis and member game behavior simulation of the evolutionary game system flow model of the members of the engineering community, discuss the feedback and evolutionary trends of the interaction of members of the engineering community, clarify the game focus and strategy choices of the members, and observe changes in auxiliary variables (target returns) under changes in exogenous variables (active returns) among game members.

\subsection{Analysis of focus in the game}

In engineering activities, members of the community play against each other to generate a focal point of confrontation. The three parties interact with each other to dynamically update the strategic adjustments given to themselves by changes in other parties:

\subsubsection{Focus of government and people}

The government is the initiator of the project construction, and the people are the object of the project. The focus of the game between the two includes the living environment, property rights, and other aspects that affect the people's interests. This directly affects the value of R2, R6, and D4. The construction of the Sanmenxia Reservoir project occupies a considerable part of the construction area and agricultural land, reducing the farming area of local people and the benefits of land transfer. After the project is launched, the local residents' compensation and welfare, such as employment, land lease and house demolition, will become the key to fight against the two kinds of games. When the benefits (R1) of the project construction to the government are sufficient compared to the paid capital (D3), the cost of assets (D4) and the benefits (R7) paid by the people to support the project remain balanced, and the government gives the people's main benefits (R2) and the capital gain (R7) obtained in support of the project meets both the government and the people's game needs, so the cooperation between the two parties will tend to "nash equilibrium".

\subsubsection{Focus of government and enterprise}

In the construction of engineering activities, in order to obtain sufficient land gain and high-quality social development effects, the government must provide different levels of preferential policies to other members of the engineering community, which determines that R1, $\mathrm{R} 2$, D1, and D3 are far larger than other exogenous variable. An enterprise is an organization that seeks to maximize its own revenue. When choosing whether to participate in project development, the company first considers the profit and loss allowance given to it by the engineering activities and the difference in revenue from participating in other projects. The government's preference (R1) is the most important concern. Therefore, the focus of the game between the two parties is the difference between their respective capital investment in engineering activities and fiscal revenue.

\subsubsection{Focus of people and enterprise}

The main factor for people to support the construction of the project is not only the income from social security, R2 and R3, but also the income from land lease and demolition compensation within the scope of project lease, such as R5 and R7. For enterprises, in order to pursue the maximization of benefits, the willingness to negotiate with the people to resolve the payment of income is low. Therefore, the demolition, compensation and rent issues under the influence of engineering activities have become the focus of the game between the people and the enterprise.

\subsection{Choices of game strategy}

The engineering activities of the Sanmenxia Reservoir involve many aspects of socio-economic and ecological environment. Solving the problem from a certain angle will lead to the deviation of construction activities and bring about new engineering problems. It is necessary to quantitatively study the members of the community (government-enterprise-people) game strategy choices. The members of the three parties will adjust their own strategies according to the benefits of transformation in the construction activities, and take engineering ethics as the direction of strategic guidance, mainly as follows. First of all, in terms of government, there are two strategies that may be selected in engineering activities: "provide preferential benefits based on utilitarian theory; bear construction costs based on obligation theory", which affect the evolutionary trend and data selection of multiple variables, such as A1, A2, R1, R2, R4, D1, D3, etc. The main consideration is the capital investment capacity and the amount of income to be obtained under these two strategies. Secondly, for enterprises, the main strategic choices are "participation in construction; nonparticipation in construction", which affects A5, A6, R8, R9 and so on. As a profit organization, the company always pursues the most refined and long-term return on investment methods. The choice of strategy mainly considers whether the income from participating in the project is sufficient and the income from participating in other projects is compared. In the end, the people's strategic choices include "obtaining benefits based on contract theory; obtaining benefits based on utilitarian theory", affecting R1, R2, R4, D1, D3, and so on. In actual engineering activities, the people are at a 
disadvantage. The government and enterprises will forcibly start construction for socio-economic development and land value enhancement. For this reason, the people's strategic choices are greatly restrained by the government and enterprises, and they are extremely sensitive to changes in their strategies.

\subsection{Simulation of Game Results}

\subsubsection{Interactive game between government and people}

Look for the strategic choices of the government and the people under the contract theory and utilitarian theory, and separate the exogenous variable R6 under the contract theory (benefit from the government to support the government) and the exogenous variable R5 under the utilitarian theory (benefit from the construction to the people) increase "-20, 0, 20, 40" percentage points, control other variables, and perform simulation comparison.

From the analysis of the simulation results in Figures 4 and 5, we can see that under the contract theory, the people's support project will give the government some benefits. After the two parties follow the contract to make the interactive income gradually balanced, the government's utilitarian construction income A1 will mutate at a specific point $(2,-100)$ and increase with the increase of R6 value; under the utilitarian theory, A4 has a small amplitude. After R5 gives the people a sufficient amount of income, the people's main body will gradually update the game strategy and choose a program with a larger return value, which will promote the abrupt change of A4 from negative to positive, and gradually obtain positive returns. The two sides repeated the game in the steps of "mutation-adjustment-rise". After both sides reached the target return or obtained higher returns, the game range slowed down to equilibrium.

\subsubsection{Conductive feedback under preferential policies enterprises as the main body}

Finding strategic choices for corporate entities to conduct game behavior between the government and the people under preferential policies, which will connect the government-enterprise exogenous variable R1 and the enterprise-people exogenous variable R3 increase "20, 0, 20, 40" percentage points, control other variables, and conduct simulation comparison.

With the evolution of the game process, if the government's returns under the two strategic choices of providing preferences and bearing development costs are balanced, the government's strategic choices and target returns will change abruptly, and the positive returns will make the government's policy preferences richer. This is the meaning of the mutation point in Figure 6. When the government provides a certain degree of preferential R1 to the enterprise, it will carefully consider the profit and loss under different strategies, adjust the preferential amount and the preferential object, and prepare for the next game strategy. However, in terms of overall efficiency, due to the pursuit of efficiency, the capital and policy support provided by the government will not be equal to and lower than the government's pursuit of utilitarian income recovery. This is a situation that the government can't avoid considering the overall situation of the project. Therefore, it is necessary to analyze the people's benefits under the government's provision of adequate corporate benefits to consider the necessity of the government's provision of preferential policies. As shown in Figure 7, the companies that have passed the government's preferential policies have given the people sufficient compensation and output, both of which show a normal upward trend, and the people's income and willingness to support increase with the increase in compensation. Consider the people's capital investment in supporting engineering activities. If the capital gains from the construction of engineering activities are not enough to offset the capital investment, and the required capital is not sufficient to bear materially and spiritually, then the subjects of the people will measure whether they need to respond to the preferential policies of the government and whether they need to invest enough capital to obtain uncertain project returns in the later period. Therefore, the A3 curve needs to exceed a certain slope. When the slope is in a proper range, people think that the benefits of supporting development and responding to government policies are more, so they will change their own strategic choices.

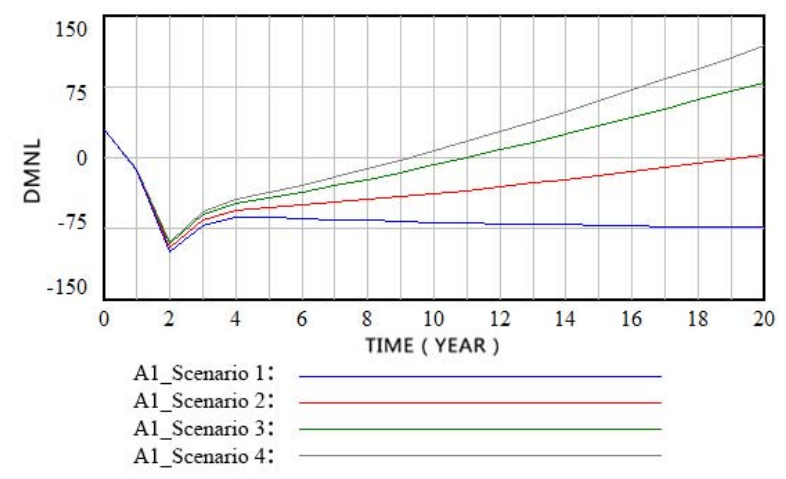

Fig. 4. Evolution of government-people game under contract theory

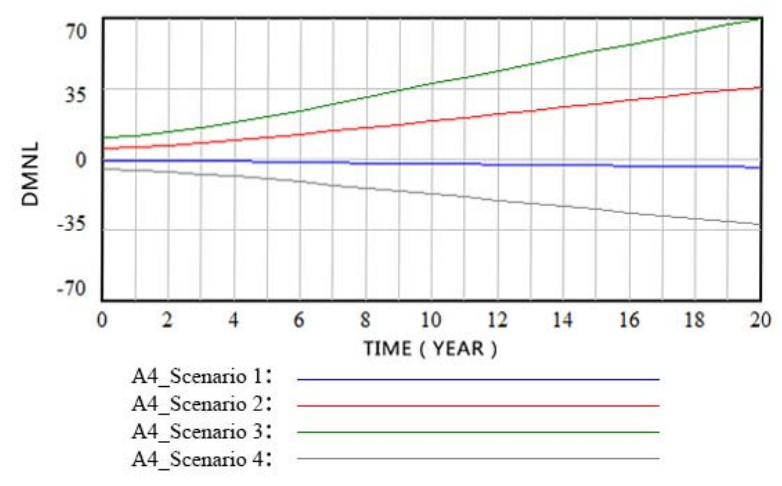

Fig. 5. Evolution of people-government game under utilitarianism 


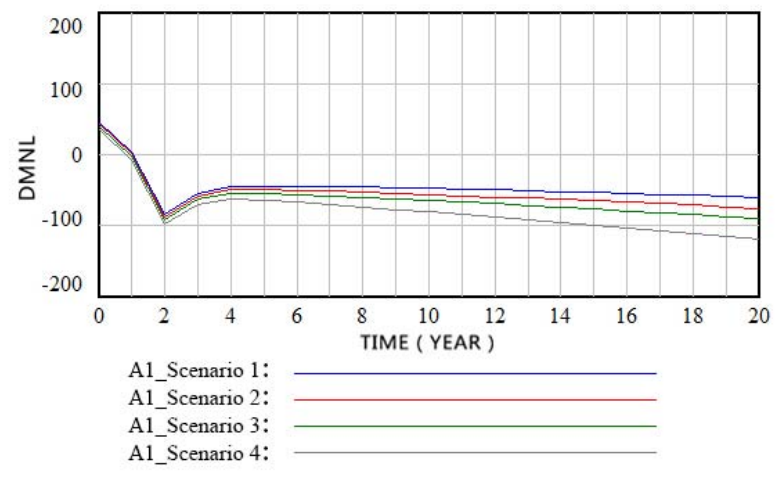

Fig. 6. Evolution of enterprise-government game under preferential policies

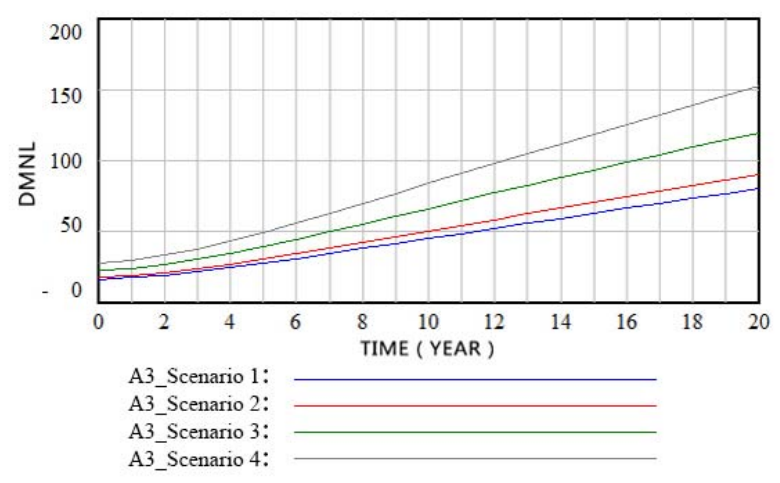

Fig. 7. Evolution of enterprise-people game under preferential policies

\section{Discuss}

\subsection{Suggestions from the perspective of the government}

\subsubsection{Engineering risk assessment and ethical responsibility}

The key to the rational plan and perfect operation of engineering activities lies in the government's risk assessment and responsibility for engineering activities. As the initiator, the government needs to control the entire life cycle of the construction of the project activities, takes good care of the policy funds and compensation, and uses the ethics and laws of the project to simultaneously guarantee the construction of the project. Moreover, the government should disclose the information and select stakeholders adhere to the principles of thoroughness and accuracy, which allows stakeholders with different ethical concerns to fully express their opinions, and propose their reasonable demands.Finally,engineering decisions can be reasonably balanced between public and expert rationality.
The government needs to ensure the stability of financial sources, and formulate compensation standards for demolition in the project reasonably and legally. In order to ensure the smooth progress of development work, it is necessary to increase financial investment, use the PPP model to attract the participation of social groups, adopt effective solutions, and make use of high availability and effective long-term resource conditions. At the same time, the government should ensure compensation, fully consider people's situation, and build a great bond between government and people.

\subsection{Suggestions from the perspective of enterprises}

\subsubsection{Emphasis on professionalism and public services}

Enterprises are involved in engineering activities by the government's funds, policies, guarantees and other multichannel preferences, and in the case of their own benefits, relevant pressure of the government will be reduced. However,as a profit-based business economy, enterprises do not have the commanding power in engineering activities, and they do not have a clear obligation to help the government guide people with low willingness to cooperate. Therefore, companies under the guidance of engineering ethics must consult with the government, emphasize professionalism and public services, and ensure that their actions are allowed by the government's legal policies which are aimed to help the government increase the people's willingness to develop, and reduce the probability of events such as forcible demolition and construction. Enterprises can express their goodwill to the public in their professional ethics by regulating their behaviors that provide services to the public.

\subsubsection{Ethical responsibility for development}

We believe that the development of ethical responsibility requires the cultivation of engineering ethical behavior, and the project leader should be responsible for the quality of engineering construction. After choosing to participate in the construction of engineering activities, enterprises must bear the ethical responsibility of development, which not only ensure the legal and reasonable compliance of engineering construction, but also ensure the compliance and inspection of project quality.

\subsection{Suggestions from the perspective of the people}

5.3.1 Follow the principles of profit and loss distribution and fairness 
People need to follow the principles of profit and loss distribution and fairness, curb the compulsory development of the government or enterprises, and safeguard their own interests. In accordance with the relevant laws and regulations, they can protect their own interests if their behaviors are correct. Based on the premise of compensation justice, punishment justice, distribution justice, and procedure justice, people can rely on the strength of the state and judicial institutions to curb unfair behaviors.

\subsubsection{Risk alert and avoidance}

There exists great uncertainty in the construction of engineering activities. People need to reasonably predict the risks alert brought by the construction of engineering activities, and try to avoid them, based on the actual situation and take the financial benefits and ecological environmental protection into account. People are the vulnerable group in engineering activities. In order to deal with the risks of uncertainty, it is necessary to take the initiative to ask the government for fair measures to ensure fair distribution in engineering activities and protect their own legitimate rights and interests and the right to survival and development. In addition, people should reasonably share the risks and benefits of the construction of engineering activities with social interest groups, and ask the society for help and compensation properly.

\section{Acknowledgments}

The research is jointly supported by the National Natural Science Foundation of China (No. 51768001) and Guangxi Natural Science Foundation Project (No. 2017JJA150076).

\section{References}

1. Murni S, Whale J, Urmee T, et al. The Role of Micro Hydro Power Systems in Remote Rural Electrification: A Case Study in The Bawan Valley, Borneo[J]. Procedia Engineering, 2012, 49:189-196.

2. Nathan S. The Big Project: London Array[J]. Engineer, 2012.

3. Vries D, MJ. Teaching Technology and Engineering. [J]. Technology \& Engineering Teacher, 2010, 70:15-19.

4. Vries M J D . The Nature of Technological Knowledge[J]. Philosophy of Technology \& Engineering Sciences, 2003, 6(3):309-350.

5. Bucciarelli L L . Engineering Philosophy[J]. international journal of machine consciousness, 2003, 02(1):V - XII.

6. Bucciarelli L L . Between thought and object in engineering design $[\mathrm{J}]$. Design Studies, 2002, 23(3):p.219-231.

7. Bo-Cong L . The Rise of Philosophy of Engineering in the East and the West[M]// Philosophy and Engineering:. Springer Netherlands, 2010.
8. Bocong L . The Rise of Philosophy of Engineering in the East and West[J]. engineering sciences, 2008.

9. Bocong Li. Human nature, the means-ends relationship, and alienation: Themes for potential East - West collaboration[J]. Technology in Society,2015,43.

10. John Clark. Engineering Business Ethics[J]. ASHRAE Journal,2016,58(2).

11. Maoto R M . The sustainability of life cycle costs in a systems engineering process of a 21 st century reliability engineering environment[J]. 2013.

12. Liu F, Pan L, Yao L H . Evolutionary Game Based Analysis for User Privacy Protection Behaviors in Social Networks[C]// 2018 IEEE Third International Conference on Data Science in Cyberspace (DSC). IEEE, 2018.

13. Liang W, Dong-Sheng C, Chang L, et al. The Variation Process and the Key Influencing Factors of Water Quality in Sanmenxia Reservoir[J]. China Rural Water and Hydropower, 2015. 